\title{
Beyond academic achievement goals: The importance of social achievement goals in explaining gender differences in self- handicapping
}

Junlin $\mathrm{Yu}^{*}$ and Ros McLellan

Faculty of Education, University of Cambridge, 184 Hills Road, Cambridge, CB2 8PQ,

United Kingdom

*Corresponding author.

Email address: junlinjy@gmail.com (J. Yu).

\section{Acknowledgements}

This research was supported by funding from the Cambridge Trust and the China Scholarship Council to the first author. We thank Pia Kreijkes, Jan Vermunt, and all anonymous reviewers for their insightful comments on earlier versions of this article. 


\title{
Beyond academic achievement goals: The importance of social achievement goals in explaining gender differences in self- handicapping
}

\author{
Boys show less adaptive behaviour and engagement than girls at school. Much \\ research has examined gender differences in academic motivation to explain \\ gender differences in school engagement. However, students engage in schools \\ both academically and socially, and gender differences in social motivation may \\ further contribute to the gender gap in academic engagement. In this study, 536 \\ secondary school students in England (ages 13-14) reported their social \\ achievement goals, academic achievement goals, and self-handicapping \\ behaviours. Boys were more likely to adopt social demonstration goals, \\ performance-approach and -avoidance goals, and reported greater behavioural \\ self-handicapping. Moreover, structural equation models showed that social \\ demonstration goals uniquely mediated the relationship between gender and self- \\ handicapping, beyond the effect of performance-avoidance goals. Results \\ highlight the importance of social achievement goals in explaining gender \\ differences in self-handicapping. The findings suggest that educators need to \\ attend to adolescents' social goals in addition to their academic goals in \\ secondary school.
}

Keywords: gender differences, motivation, social achievement goals, academic achievement goals, self-handicapping

\section{Introduction}

There are persistent gender gaps in school achievement, with girls outperforming boys around the world (OECD, 2015; Stoet \& Geary, 2015). Not only are girls ahead of boys in language and literary skills, they also achieve better grades in stereotypically masculine subjects, such as maths and science (Voyer \& Voyer, 2014). In addition, boys report lower levels of school engagement relative to girls in international studies (Lam et al., 2012). In the UK, the issue of underachieving boys has similarly received considerable attention (Younger, Warrington, \& McLellan, 2005). The gender 
achievement gap is evidenced by boys' and girls' differential performance in the highstakes General Certificate of Secondary Education (GCSE) examinations taken at the end of secondary school (Strand, 2014).

Prior work attempting to explain the gender gap in engagement or achievement has focused almost exclusively on gender differences in students' academic motivation (e.g., Kenney-Benson, Pomerantz, Ryan, \& Patrick, 2006). For instance, in a study of adolescents from the UK, boys placed lower values on learning and schoolwork, and were more interested in demonstrating their ability and outperforming others. This pattern of motivation, in turn, predicted gender differences in maladaptive classroom behaviours (Bugler, McGeown, \& St Clair-Thompson, 2015). Yet, students' academic and social lives are closely intertwined in school (e.g., Liem, 2016; Shim \& Finch, 2014). Connecting with others and feeling a sense of belonging are essential for motivation (Baumeister \& Leary, 1995; Deci \& Ryan, 2000), and the desire to fit in and gain peer acceptance can have powerful influences on adolescent behaviour (Wentzel, 2017). Although a small but growing number of studies have examined how academic and social motives jointly affect students' outcomes (e.g., Patrick, Ryan, \& Kaplan, 2007; Ryan \& Shin, 2011), gender is rarely the focus of these studies or is used only as a statistical control variable (for an exception, see Ben-Eliyahu, Linnenbrink-Garcia, \& Putallaz, 2017). Are there any differences between boys and girls in their social motivation at school? If so, how do gender differences in academic and social motivation operate synergistically to influence students' academic engagement?

The present study addresses these issues by identifying differences in adolescent boys' and girls' academic and social motivation, as well as examining their joint role in explaining gender differences in one maladaptive aspect of academic engagement, namely self-handicapping. Specifically, we adopt an achievement goal approach to 
examine motivation (Dweck, 1986; Nicholls, 1984) as it has been applied to both academic and social domains and thus provides a unified framework to understand academic and social goal pursuits. In addition, we focus on self-handicapping as an index of (maladaptive) behavioural engagement because it has been prominently featured in qualitative research as an explanation for boys' underperformance (Jackson, 2002, 2003), and has been shown to have long-term detrimental effects on student achievement (Schwinger, Wirthwein, Lemmer, \& Steinmayr, 2014). In the following sections, we review the literature on academic achievement goals, social achievement goals, and self-handicapping as well as consider the interplay among these constructs before outlining the present study.

\subsection{Academic achievement goals}

Academic achievement goals are defined as the underlying reasons or purposes for engaging in a learning task (Elliot, 2005). Initially, two types of achievement goals were identified: mastery goals, where students focus on developing their academic competence, and performance goals, where students focus on demonstrating their competence to others (Dweck, 1986; Nicholls, 1984). Later, Elliot and Harackiewicz (1996) introduced the approach-avoidance distinction to performance goals, resulting in a trichotomous model of achievement goals comprised of mastery, performanceapproach, and performance-avoidance goals. Students with performance-approach goals aim to demonstrate high academic competence to others, and those with performanceavoidance goals aim to avoid looking incompetent relative to others. Although more complex achievement goal frameworks have been proposed and investigated in recent years (see Vansteenkiste, Lens, Elliot, Soenens, \& Mouratidis, 2014), we utilise the trichotomous framework in this study to stay consistent with the research on social achievement goals (see Section 1.2). 
The influence of academic achievement goals on students' motivation and engagement has been widely documented. The pursuit of mastery goals has been linked to a host of positive outcomes, including increased enjoyment, interest, engagement and well-being at school (Huang, 2011; Wormington \& Linnenbrink-Garcia, 2017). In contrast, pursuing performance-avoidance goals has been consistently associated with maladaptive outcomes, such as heightened test anxiety (Huang, 2011), increased selfhandicapping (Urdan, 2004), reduced feedback seeking (Payne, Youngcourt, \& Beaubien, 2007), and deteriorating performance (Hulleman, Schrager, Bodmann, \& Harackiewicz, 2010). The outcomes of adopting performance-approach goals have been mixed and partly depend on how these goals are defined. Performance-approach goals are generally maladaptive when they emphasize competence demonstration, but can lead to positive outcomes when they focus on outperforming others (Senko \& Dawson, 2017).

Despite the proliferation of research on achievement goals, only a small subset of studies have reported gender differences (Butler \& Hasenfratz, 2017; Hyde \& Durik, 2005), and few have examined how these differences in achievement goals may translate into gender differences in engagement and achievement. Previous studies tend to show that adolescent girls are more mastery-oriented than boys (Bugler et al., 2015; Kenney-Benson et al., 2006; King, 2016a; Nie \& Liem, 2013), though some studies found no such gender differences in maths (Friedel, Cortina, Turner, \& Midgley, 2007; Preckel, Goetz, Pekrun, \& Kleine, 2008). There is also a trend for adolescent boys to report higher levels of performance goal pursuit (Butler, 2006; Friedel et al., 2007; Preckel et al., 2008), although several studies observed no differences at all (King, 2016a; Nie \& Liem, 2013). Given the somewhat mixed results and the importance of 
task domain in shaping motivation, researchers should continue to investigate gender differences in achievement goals across a variety of domains.

As mentioned, mastery and performance goals have been linked to different outcomes. Since boys tend to prioritise performance over mastery goals, gender differences in academic goal pursuit may partially underlie the gender differences in engagement and achievement. Indeed, Kenney-Benson et al. (2006) found that adolescent boys reported higher levels of performance goals, as well as lower levels of self-regulated learning and persistence. These differences in learning behaviours, in turn, predicted boys' lower grades over a two-year period. However, as with much of the literature on gender gaps in education, this study only considered differences in academic motivation to explain the gender differences in engagement and performance.

\subsection{Social achievement goals}

Social achievement goals reflect the reasons why people engage in interpersonal behaviours and represent broad orientations towards achieving social competence (Ryan $\&$ Shim, 2006, 2008). This is different from a focus on the specific social outcomes that people wish to achieve, such as affiliation, intimacy, or approval (Patrick, Anderman, \& Ryan, 2002). Analogous to academic achievement goals, three types of social achievement goals have been identified (Ryan \& Shim, 2008): A social development goal involves developing positive peer relationships and improving social competence; a social demonstration-approach goal concerns demonstrating social competence and gaining favourable judgments from others (e.g., being seen as cool or popular); a social demonstration-avoidance goal involves hiding the lack of social competence and avoiding negative judgments from others (e.g., not being seen as socially awkward, or as a 'nerd' or 'geek'). 
Social achievement goals have been linked to a range of social outcomes in school settings. For example, social development goals are related to increased prosocial behaviours, a greater sense of belonging, social satisfaction, and well-being (Mouratidis \& Sideridis, 2009; Ryan \& Shim, 2006; Shim, Cho, \& Wang, 2013). In contrast, social demonstration-avoidance goals are primarily associated with maladaptive consequences, including anxious or avoidant behaviour, loneliness, as well as reduced social efficacy and well-being (Mouratidis \& Sideridis, 2009; Ryan \& Shim, 2006, 2008; Shim et al., 2013). Social demonstration-approach goals have been linked to increased popularity but also increased aggressive behaviour and social worry (Ryan \& Shim, 2008; Shim et al., 2013).

Of particular interest to the present study is that students' social achievement goals can exert cross-domain influences on their academic outcomes. A focus on building close relationships with peers has been associated with increased levels of effort, engagement, interest, and enjoyment in the classroom (Kiefer \& Ryan, 2008; Shim et al., 2013). A concern with demonstrating social competence and gaining high social status has been associated with lower help-seeking tendencies (Ryan \& Shin, 2011), lower academic effort, persistence and self-regulated learning (Liem, 2016), as well as increased performance goal pursuit (Anderman \& Anderman, 1999). Similarly, a social demonstration-avoidance goal has been linked to primarily maladaptive academic outcomes, including lower classroom engagement (Ben-Eliyahu et al., 2017).

Studies have also reported gender differences regarding students' social goals. From middle childhood to adolescence, girls are more concerned with forming and maintaining positive peer relationships (e.g., Anderman \& Anderman, 1999; Kiefer, Matthews, Montesino, Arango, \& Preece, 2013; Kiefer \& Ryan, 2008). Boys, on the contrary, tend to focus more on gaining and maintaining social status in their peer 
groups (e.g., Anderman \& Anderman, 1999; Ben-Eliyahu et al., 2017; Kiefer et al., 2013; Kiefer \& Ryan, 2008; LaFontana \& Cillessen, 2010). Given that social development and social demonstration goals show differential relations to school engagement and learning strategies, girls' stronger social development goals may be considered more adaptive. In contrast, boys' greater tendency to pursue social demonstration goals, coupled with their stronger orientation towards performance goals, may further exacerbate their academic engagement and achievement. Consequently, more research is needed to understand how social goals may operate in tandem with academic goals to facilitate or hinder boys' and girls' academic outcomes.

\subsection{Academic self-handicapping}

Academic self-handicapping involves intentionally creating obstacles prior to an achievement activity to provide an excuse for potential poor performance (Urdan \& Midgley, 2001). This shifts the attributions for task failure away from low ability, thereby protecting a sense of self-worth and perceptions of competence (Covington \& Omelich, 1979). Examples of academic self-handicapping include procrastinating, staying up late before an important task, as well as not studying for an exam or being underprepared for it. Additionally, the literature draws a distinction between behavioural and claimed self-handicapping, the latter of which involves merely claiming an obstacle but not engaging in intentional acts that reduce the likelihood of success (Urdan \& Midgley, 2001). In this paper we focus on behavioural forms of selfhandicapping for two reasons. Firstly, they reflect maladaptive engagement at school and are likely to undermine academic performance directly. Indeed, a recent metaanalysis (Schwinger et al., 2014) found a negative relationship between selfhandicapping and academic achievement $(r=-.23)$. Secondly, there are rather robust 
yet puzzling gender differences: males are more likely to engage in behavioural but not claimed self-handicapping (Dietrich, 1995; McCrea, Hirt, \& Milner, 2008).

Gender differences in behavioural self-handicapping have been difficult to explain. One mechanism that has received empirical support points to the differential valuing of effort between genders. In a series of studies, Hirt, McCrea and colleagues found that young women ascribed higher personal values to effort and were more critical of people who self-handicapped. This, in turn, led them to refrain from selfhandicapping (Hirt, McCrea, \& Boris, 2003; McCrea, Hirt, Hendrix, Milner, \& Steele, 2008; McCrea, Hirt, \& Milner, 2008).

Research has also linked academic achievement goals to self-handicapping and found rather clear and consistent patterns. In the face of potential failure, students who adopt performance-avoidance goals (vs. performance-approach goals) tend to purposely reduce effort to avoid inferences of low ability (i.e., 'I didn't try' as an excuse for failure; Leondari \& Gonida, 2007; Midgley \& Urdan, 2001; Urdan, 2004). Conversely, highly mastery-oriented students are less likely to engage in self-handicapping (Leondari \& Gonida, 2007; Rhodewalt, 1994; Schwinger \& Stiensmeier-Pelster, 2011). Interestingly, gender differences in self-handicapping are mirrored by gender differences in academic achievement goals. Therefore, the differential tendencies among boys and girls to pursue performance or mastery goals may partially explain the gender differences in self-handicapping. However, this mechanism has not yet been directly tested.

In addition to ability-related concerns, self-handicapping in the form of effort withdrawal may be further driven by students' social motives. Research has shown that academic effort is inversely related to status and popularity during adolescence, and that low effort helps young people to gain peer approval and popularity (Heyder \& Kessels, 
2017; Juvonen \& Murdock, 1995). As a result, students who seek to attain high status or avoid a fall in peer status may be particularly likely to self-handicap or withdraw effort to preserve a 'cool' image. Initially, some researchers theorised that the link between low effort and popularity might be stronger for boys, thereby prompting them to selfhandicap more (Jackson, 2002, 2003). However, both observational and experimental studies show that low effort enhanced boys' and girls' perceived popularity to the same degree, suggesting that girls also need to withhold effort to gain high peer group status (Heyder \& Kessels, 2017; Jackson, 2006; Juvonen \& Murdock, 1995).

Given that both genders view strategic effort withdrawal as promoting peer approval and popularity, gender differences in self-handicapping may instead be driven by boys' greater concerns for peer status and popularity (i.e., social demonstration goals). Research suggests that boys are preoccupied with social status and peer approval during adolescence (LaFontana \& Cillessen, 2010). As a result, gender differences in social achievement goals may further contribute to the gender differences in selfhandicapping, especially in the form of effort withdrawal. Overall, a better understanding of the motivational processes underlying gender differences in selfhandicapping is needed to pinpoint potential ways to reduce boys' maladaptive engagement at school.

\subsection{The present study}

In the present study, we investigate the joint role of academic and social achievement goals in explaining gender differences in self-handicapping. Specifically, our paper seeks to answer the following questions:

Research Question 1: Are there gender differences in academic achievement goals, social achievement goals, and academic self-handicapping? 
Research Question 2: Can academic and social achievement goals partly explain gender differences in self-handicapping?

As discussed earlier, gender differences in academic motivation are likely to be domain-specific. Yet, existing studies tend to examine motivation with respect to school in general or in one specific domain such as maths. Thus, one contribution of the current study is that we investigate gender differences across two gender-typed subjects (i.e., English and maths) to assess the extent to which our findings are robust or limited to a particular task domain.

Based on prior literature, we expected adolescent boys to show less adaptive patterns of motivation and engagement relative to girls (Hypothesis 1). Specifically, boys would report higher levels of performance goals, social demonstration goals, and self-handicapping behaviours. In contrast, girls would be more likely than boys to espouse mastery goals. We also expected the gender differences to be larger in English, as it represents an area where boys are stereotypically expected to perform less well.

Furthermore, we predicted that gender differences in academic and social achievement goals would collectively explain the relationship between gender and selfhandicapping (Hypothesis 2). As can be seen in Figure 1, we pitted these two competing mechanisms against each other in the same model. This enabled us to compare the strength of indirect pathways, and to test whether each indirect effect was significant after controlling for the other. Thus, it provides a strong test of our proposal. Given the more consistent links between performance-avoidance goals and self-handicapping in past studies, we hypothesised that performance-avoidance goals, rather than performance-approach goals, would mediate the association between gender and selfhandicapping. We also predicted that social demonstration goals would independently 
mediate the relation between gender and self-handicapping, beyond the effect of performance-avoidance goals. However, due to a lack of prior studies linking social achievement goals to academic self-handicapping, we did not have strong hypotheses about which forms of social demonstration goals might relate more strongly to selfhandicapping.

[Insert Figure 1 here]

\section{Method}

The dataset analysed in the present study is part of a larger mixed-methods study entitled Laddishness and Self-Worth Protection (Jackson, 2008), made publicly available by the UK Data Service (an online repository for publicly-funded research data in the UK). Although the author of the original study has published several papers based on the qualitative interviews, there has been no systematic investigation of the quantitative survey data. Therefore, our paper presents a secondary analysis of the survey data from the project. The institution where the original author was based granted ethical approval for the data collection.

\subsection{Participants and procedure}

Participants were Year 9 students (13-14 years old) from six secondary schools in the north of England. Of the six schools, four were co-educational, one was single-sex boys, and one was single-sex girls. Participating schools were diverse in terms of social class, ethnicity, and academic attainment. At the time of data collection, school-level statistics indicated that the percentage of students eligible for free school meals (a proxy for low income) in each school ranged from 3 to $51 \%$; the proportion of ethnic minority 
students ranged from 1 to $86 \%$; the proportion of students reaching the benchmark in national examinations (five or more GCSE passes) at age 16 ranged from 16 to $83 \%$. A detailed breakdown of student characteristics by school can be found in Table 1 .

\begin{tabular}{lccccc}
\hline School & Type & $\begin{array}{c}\text { No. of } \\
\text { participants }\end{array}$ & $\begin{array}{c}\text { \% Ethnic } \\
\text { minority }\end{array}$ & $\begin{array}{c}\text { \% Low } \\
\text { income }\end{array}$ & $\begin{array}{c}\text { \% Passing 5+ } \\
\text { GCSEs }\end{array}$ \\
\hline 1 & Co-educational & 131 & 23 & 19 & 54 \\
2 & Co-educational & 89 & 1 & 21 & 28 \\
3 & Co-educational & 53 & 31 & 51 & 16 \\
4 & Co-educational & 63 & 86 & 42 & 38 \\
5 & Single-sex girls & 118 & 17 & 9 & 70 \\
6 & Single-sex boys & 82 & 5 & 3 & 83 \\
\hline
\end{tabular}

Table 1. Student characteristics for each school at the time of data collection

Participants completed a set of three scales in paper-and-pencil form during the school day. Two of the scales explored students' academic goals and self-handicapping behaviours in English and maths. A third scale assessed students' social goals in school. A sample item, along with the rating scale, was first presented to students. Students were told that the purpose of the survey was to better understand their attitudes towards school and schoolwork, that it was not a test, and that their answers would be kept confidential.

For the purposes of this study, we limited our analysis to participants who had completed all three scales. To ensure data quality, the analytic sample excluded 17 participants with more than $20 \%$ missing data and 51 participants who used the same response option for more than 10 consecutive items, which were exclusion criteria established a priori. The final sample consisted of 536 participants (285 girls) and was ethnically diverse (75.8\% White, 22\% Asian, 1.7\% mixed race, and 0.6\% Black).

\subsection{Measures}

The survey assessed the following: academic and social goal orientations, academic 
self-handicapping, and demographic information. All main items were rated on a scale that ranged from 1 (not at all true) to 5 (very true).

\subsubsection{Academic achievement goals}

Academic goal orientations were assessed domain specifically across maths and English, using a 14-item scale adapted from the Patterns of Adaptive Learning Survey (PALS; Midgley et al., 2000). Mastery goal items focus on developing academic competence (5 items; 'It's important to me that I improve my ... skills this year'). Performance-approach items focus on demonstrating and affirming academic competence to others ( 5 items; 'One of my goals is to show others that ... is easy for me'). Performance-avoidance goal items focus on demonstrating that one does not lack academic competence ( 4 items; 'One of my goals in ... is to avoid looking like I have trouble doing the work').

We sought to verify the three-factor structure using confirmatory factor analyses (CFAs). Model fit was assessed using the comparative fit index (CFI), the root mean square error of approximation (RMSEA), and the standardised root mean-square residual (SRMR). Good model fit was indicated by a CFI value close to .95 or above, a RMSEA value close to .06 or below, and SRMR close to .08 or below (Hu \& Bentler, 1999). The three-factor model provided an excellent fit to the data $(\mathrm{CFI}=.944$, RMSEA $=.051, \mathrm{SRMR}=.047$ for maths; $\mathrm{CFI}=.964, \mathrm{RMSEA}=.045, \mathrm{SRMR}=.049$ for English). An alternative two-factor model with a mastery goal and a performance goal yielded a worse fit $(\mathrm{CFI}=.922, \mathrm{RMSEA}=.059, \mathrm{SRMR}=.052$ for maths; $\mathrm{CFI}=.949$, $\mathrm{RMSEA}=.053, \mathrm{SRMR}=.053)$. In the three-factor model, however, there was considerable overlap between performance-approach and performance-avoidance goals $(\phi=.80$ in maths and .86 in English; see also Bong, Woo, \& Shin, 2013). 
Omega hierarchical coefficient $\left(\omega_{h}\right)$ was used to estimate the reliability of the scales. Omega hierarchical is highly advantageous because it makes more appropriate assumptions than Cronbach's alpha (McNeish, 2018) while assessing how well the items measure a single latent factor (Revelle \& Zinbarg, 2009). Reliability estimates were .84 and .89 for mastery goals in maths and English; .86 and .90 for performanceapproach goals in maths and English; .73 and .79 for performance-avoidance goals in maths and English.

\subsubsection{Social achievement goals}

Social goal orientations were assessed using items constructed by the author of the original study (Jackson, 2008). These items were similar to those used by Ryan and Shim $(2006,2008)$ and asked about social goals in school. Demonstration-approach goals focused on demonstrating social competence and status (5 items, $\omega_{h}=.92$; 'It's important to me that other students in my school think I'm cool'). Demonstrationavoidance goals focused on avoiding the demonstration of social incompetence (3 items, $\omega_{h}=.77$; 'One of my goals is to keep others from thinking I'm not cool'). There was no measure of social development goals.

To further evaluate the items developed by the original author, we conducted CFAs to compare a two-factor model (approach and avoidance items loading on separate factors) with a one-factor model (approach and avoidance items loading on the same factor). Results showed that the one-factor model fitted the data very well (CFI = $.954, \mathrm{RMSEA}=.071, \mathrm{SRMR}=.034)$. Although the two-factor model showed a slight improvement in fit $(\mathrm{CFI}=.960, \mathrm{RMSEA}=.068, \mathrm{SRMR}=.031)$, a closer inspection revealed an extremely high correlation between the two factors $(\phi=.93)$. This suggests that participants in this study did not adequately distinguish between approach and 
avoidance forms of social goals. To avoid multicollinearity and interpretation problems, we collapsed all eight items in subsequent analyses to form a general social demonstration goal $\left(\omega_{h}=.92\right)$.

\subsubsection{Academic self-handicapping}

Self-handicapping in maths and English was assessed using the six-item Academic SelfHandicapping Scale from the PALS (Midgley et al., 2000). This scale measures the use of active, behavioural forms of self-handicapping to provide a priori excuses for possible failures. A sample item of the scale is: 'Some students put off doing their ... work until the last minute so that if they don't do well they can say that is the reason. How true is this of you?' Omega hierarchical coefficients were .88 and .92 for selfhandicapping in maths and English.

\subsubsection{Covariates}

The present study investigates the extent to which academic and social goals might mediate the relationship between gender and self-handicapping. Thus, it is important to include appropriate covariates to identify the unique variance attributable to gender. Ethnicity was reported by students at the beginning of the survey and was included as a covariate in latent variable models. Furthermore, as can be gleaned from Table 1, there was a strong connection between school type (single-sex vs. co-educational) and the school's average level of socio-economic status (SES) and achievement, such that students attending single-sex schools tended to come from more affluent backgrounds and perform better in secondary school. Since the dataset did not contain students' SES and prior achievement at the individual level, we decided to include the type of school that students attended as another covariate. We argue that this approach provides some, albeit imperfect, control over the effects of SES and prior achievement. The effects of 
ethnicity and school type are also reported along with the central findings. However, the effects of school type should be interpreted with caution, as it is unclear whether these effects were driven by gender composition of peers, school average SES, or school average achievement.

\subsection{Statistical analyses}

Latent variable modelling was performed in Mplus Version 8.1 (Muthén \& Muthén, 1998-2017) using the robust likelihood estimator (MLR). Additionally, missing data was handled with the full information maximum likelihood estimation provided by Mplus. The analysis proceeded in three steps. First, we examined whether the measurement models were equivalent across gender. Based on these results, we then compared gender differences in latent means. Lastly, we tested the hypothesised relationships between gender, academic and social goal orientations, as well as selfhandicapping using structural equation modelling (SEM).

\subsubsection{Measurement invariance}

We sought to establish measurement invariance to ensure that comparisons of group means are valid. Evidence of measurement invariance can be established by fitting a series of multigroup CFA models with increasing levels of cross-group equality constraints (Gregorich, 2006). Configural invariance is examined first and is supported if the factor structure of a measure is the same across groups. The next step is to test for weak (or metric) invariance by constraining factor loadings to be equal across groups. This is followed by strong (or scalar) invariance, which is established by introducing equality constraints on the item intercepts and indicates that response differences across groups are directly related to differences in the latent variables. If a given level of full measurement invariance is untenable, partial invariance may be tested by freeing some 
of the constraints, and comparisons of means are restricted to those items meeting the invariance criteria. It is important to note that comparisons of group means are meaningful only if strong or partial strong invariance holds (Gregorich, 2006).

To determine invariance, we evaluated whether changes in model fit statistics were within acceptable ranges. According to the cutoff criteria defined by Chen (2007), weak invariance is supported if $\Delta \mathrm{CFI}<.010, \Delta \mathrm{RMSEA}<.015$, and $\triangle \mathrm{SRMR}<.030$, and strong invariance is supported if $\Delta \mathrm{CFI}<.010, \Delta \mathrm{RMSEA}<.015$, and $\Delta \mathrm{SRMR}<.010$.

\subsubsection{Gender differences}

After establishing measurement invariance, we compared mean differences in latent constructs between genders. Girls were set as the reference group and the latent means for boys were freely estimated to produce the relative differences, correcting for measurement error. Mean differences for multiple latent variables were estimated simultaneously with other parameters, thereby avoiding the problem of inflated Type I error rates associated with conducting multiple comparisons.

\subsubsection{Mediational pathways}

Prior to testing the central mediation model, we sought to replicate previous findings and confirm the relative importance of performance-avoidance goals (vs. performanceapproach goals) in predicting the use of self-handicapping strategies. Given the strong correlations between approach and avoidance forms of academic goals in the current study and in previous research (Bong et al., 2013; Linnenbrink-Garcia et al., 2012), we conducted commonality analysis in $\mathrm{R}$ to gauge the relative contribution of each type of performance goal to self-handicapping. Commonality analysis has advantages over multiple regression because it explicitly addresses the problem of multicollinearity. Specifically, commonality analysis partitions the explained variance in the outcome 
variable into portions uniquely explained by a given predictor as well as jointly explained by all predictors (Nimon, Lewis, Kane, \& Haynes, 2008). As a result, it quantifies the contribution of each predictor and helps to determine the most important predictor in the presence of highly correlated factors.

Next, we estimated a parallel mediator model where both performanceavoidance goals and social demonstration goals were included as potential mediators (see Figure 1), and tested the proposal that social demonstration goals would account for gender differences in self-handicapping beyond the effects of performanceavoidance goals. To formally assess the indirect relations between gender and selfhandicapping via social and academic goals, we used a bootstrapping procedure with 10,000 bootstrap samples and $95 \%$ bias-corrected confidence intervals (CIs). We relied on bootstrap CIs to determine the significance of mediated effects because, unlike $p$ values, bootstrap CIs do not impose the rigid assumption of normality and have been shown to yield greater power to detect indirect effects (Preacher \& Hayes, 2008). Significant mediation is indicated by a CI that does not contain zero (Fritz \& MacKinnon, 2007).

\section{Results}

\subsection{Preliminary analyses of means and correlations}

Table 2 presents the means and standard deviations among the observed variables separately for each gender. Mean level differences between boys and girls were observable for performance goals (both approach and avoidance forms), social demonstration goals, and self-handicapping. Thus, we proceeded to test measurement invariance and formally compare the latent means across gender. 
Table 3 shows the intercorrelations among the observed variables for boys and girls. As is clear from the table, self-handicapping was inversely related to mastery goals, but positively associated with performance and social demonstration goals. Furthermore, the associations between performance and social demonstration goals were only moderate $(r \mathrm{~s}=.28$ to .39$)$, suggesting that students' goals in academic and social domains were relatively distinct.

\begin{tabular}{lcccc}
\hline & \multicolumn{2}{c}{ Girls } & \multicolumn{2}{c}{ Boys } \\
\cline { 2 - 5 } & $\mathrm{M}$ & $\mathrm{SD}$ & $\mathrm{M}$ & $\mathrm{SD}$ \\
\hline English mastery goal & 4.00 & 0.88 & 3.90 & 0.89 \\
English performance-approach goal & 2.00 & 0.93 & 2.48 & 1.01 \\
English performance-avoidance goal & 2.30 & 0.99 & 2.52 & 0.94 \\
English self-handicapping & 1.68 & 0.81 & 1.92 & 0.89 \\
Maths mastery goal & 3.87 & 0.87 & 3.89 & 0.79 \\
Maths performance-approach goal & 2.01 & 0.88 & 2.48 & 1.00 \\
Maths performance-avoidance goal & 2.34 & 0.91 & 2.61 & 0.95 \\
Maths self-handicapping & 1.79 & 0.79 & 2.03 & 0.90 \\
Social demonstration goal & 1.93 & 0.80 & 2.33 & 0.92 \\
\hline
\end{tabular}

Table 2. Means and standard deviations for observed variables by gender 


\begin{tabular}{|c|c|c|c|c|c|c|c|c|c|}
\hline & 1 & 2 & 3 & 4 & 5 & 6 & 7 & 8 & 9 \\
\hline 1. English mastery goal & & .18 & .16 & -.31 & .71 & .19 & .17 & -.25 & $-.03^{\mathrm{a}}$ \\
\hline 2. English performance-approach goal & .30 & & .72 & .20 & .11 & .71 & .54 & .17 & .39 \\
\hline 3. English performance-avoidance goal & .25 & .70 & & .21 & $.09^{\mathrm{a}}$ & .53 & .64 & .19 & .40 \\
\hline 4. English self-handicapping & -.30 & .12 & .20 & & -.28 & .15 & .20 & .78 & .31 \\
\hline 5. Maths mastery goal & .62 & .21 & .23 & -.15 & & .24 & .14 & -.26 & $-.09^{\mathrm{a}}$ \\
\hline 6. Maths performance-approach goal & .40 & .62 & .58 & .16 & .29 & & .57 & .22 & .34 \\
\hline 7. Maths performance-avoidance goal & .26 & .54 & .63 & .23 & .17 & .61 & & .25 & .42 \\
\hline 8. Maths self-handicapping & -.21 & .12 & .20 & .80 & -.20 & .14 & .21 & & .35 \\
\hline 9. Social demonstration goal & $.00^{\mathrm{a}}$ & .39 & .35 & .19 & $-.07^{\mathrm{a}}$ & .37 & .28 & .20 & \\
\hline
\end{tabular}

Note. Values for girls are above the diagonal and for boys below the diagonal. All correlations are significant at $p<.05$ unless otherwise indicated.

${ }^{\mathrm{a}}$ Nonsignificant correlation.

Table 3. Intercorrelations among observed variables by gender 


\subsection{Measurement invariance}

Multigroup CFAs were performed for all three questionnaires separately to determine measurement invariance across boys and girls. Fit indices for these models are shown in Table 4. For academic goals and self-handicapping in English, the unconstrained model (Model 1a) provided a good fit for the data. A series of increasingly restrictive constraints on the measurement models did not lead to significant decreases in model fit (Models $1 \mathrm{~b}$ and $1 \mathrm{c}$ ). In particular, the changes in CFI were small and well below the .010 margin suggested by Chen (2007). Collectively, the results suggested that academic goal orientations and self-handicapping in English were fully invariant across gender at the configural, metric, and scalar levels.

For academic goal orientations and self-handicapping in maths, the unconstrained and loading-invariant models (Models 2a and 2b) exhibited satisfactory fit and the changes in fit indices were negligible $(\Delta \mathrm{CFI}=.001, \Delta \mathrm{RMSEA}=.001$, $\Delta \mathrm{SRMR}=-.003)$. The model fit was also adequate when item intercepts were held equal across groups $(\mathrm{CFI}=.939, \mathrm{RMSEA}=.041, \mathrm{SRMR}=.062)$, but the drop in CFI $(\Delta \mathrm{CFI}=.012)$ slightly exceeded the .010 threshold, suggesting that the condition of full scalar invariance was not met. We thus examined modification indices and assessed partial scalar invariance. One mastery goal item ('It's important to me that I improve my maths skills this year') had high modification indices and, as such, the intercept constraint on this item was freed. The resulting model (Model 2c) had a good fit to the data as well as acceptable changes in fit indices $(\Delta \mathrm{CFI}=.009, \Delta \mathrm{RMSEA}=-.003$, $\Delta \mathrm{SRMR}=-.002)$, thus passing the test of partial scalar invariance. 


\begin{tabular}{lcccccccc}
\hline \multicolumn{1}{c}{ Model } & $\chi^{2}$ & $d f$ & CFI & RMSEA & SRMR & $\Delta$ CFI & $\Delta$ RMSEA & $\Delta$ SRMR \\
\hline English goals and self-handicapping & & & & & & \\
1a Configural & 511.499 & 328 & .947 & .046 & .062 & & & \\
1b Metric & 535.577 & 344 & .944 & .046 & .067 & .003 & .000 & -.005 \\
1c Full scalar & 573.598 & 360 & .938 & .047 & .069 & .006 & -.001 & -.002 \\
Maths goals and self-handicapping & & & & & & \\
2a Configural & 454.531 & 328 & .952 & .038 & .057 & & & \\
2b Metric & 472.764 & 344 & .951 & .037 & .060 & .001 & .001 & -.003 \\
2c Partial scalar 509.963 & 359 & .942 & .040 & .062 & .009 & -.003 & -.002 \\
Social demonstration goals & & & & & & & \\
3a Configural & 73.296 & 38 & .971 & .059 & .033 & & & \\
3b Metric & 86.935 & 45 & .966 & .059 & .053 & .005 & .000 & -.020 \\
3c Partial scalar & 102.525 & 51 & .958 & .061 & .051 & .008 & -.002 & .002 \\
\hline
\end{tabular}

Table 4. Summary of model fit statistics for testing measurement invariance across gender

The invariance of the social goal measure was assessed next. Fit indices for the unconstrained and loading-invariant models (Models 3a and 3b) were excellent and the equality constraints did not lead to a significant worsening in fit $(\Delta \mathrm{CFI}=.005$, $\Delta \mathrm{RMSEA}=.000, \Delta \mathrm{SRMR}=-.020)$. The model fit was good when equality constraints were imposed on item intercepts $(\mathrm{CFI}=.952, \mathrm{RMSEA}=.065, \mathrm{SRMR}=.053)$, but the change in CFI $(\Delta \mathrm{CFI}=.014)$ slightly exceed the .010 criterion, indicating that the full form of scalar invariance may not be appropriate. We thus examined modification indices and subsequently relaxed the intercept constraint on one social demonstrationapproach item ('One of my goals is to show others that I'm cool'). The resulting model (Model 3c) was a good fit and the changes in fit indices remained in an acceptable range $(\Delta \mathrm{CFI}=.008, \Delta \mathrm{RMSEA}=-.002, \Delta \mathrm{SRMR}=.002)$. The condition of partial scalar invariance was therefore met.

Overall, the results showed that our measures of academic goals, social goals, and self-handicapping were largely invariant across gender, providing a sound psychometric basis for comparing latent means between boys and girls. 


\subsection{Gender differences in academic goals, social goals, and self-handicapping}

Latent means were estimated based on the items that achieved strong factorial invariance. Girls were set as the reference group, and the latent means of boys represented differences in means relative to girls (see Table 5). Furthermore, we computed effect sizes (Cohen's $d$ ) to demonstrate the magnitude of gender differences. Cohen (1992) suggested that a value of .20 be considered a small effect, .50 a medium effect, and .80 a large effect.

\begin{tabular}{lcrc}
\hline \multicolumn{1}{c}{ Variable } & Latent mean & $p$ & Cohen's $d$ \\
\hline English mastery goal & -.146 & .139 & .15 \\
English performance-approach goal & .583 & $<.001$ & .55 \\
English performance-avoidance goal & .270 & .008 & .29 \\
English self-handicapping & .364 & .001 & .33 \\
Maths mastery goal & .086 & .364 & .09 \\
Maths performance-approach goal & .584 & $<.001$ & .51 \\
Maths performance-avoidance goal & .371 & .001 & .37 \\
Maths self-handicapping & .353 & .002 & .30 \\
Social demonstration goal & .484 & $<.001$ & .57 \\
\hline
\end{tabular}

Table 5. Latent mean differences for boys and girls (positive values indicate higher scores for boys)

We hypothesised that girls were more mastery-oriented and less performanceoriented than boys. As hypothesised, boys endorsed more performance-approach goals in English $(d=.55)$ and maths $(d=.51)$. They were also more oriented towards performance-avoidance goals in English $(d=.29)$ and maths $(d=.37)$. Inconsistent with our hypothesis, however, we did not find any significant gender differences in mastery goal pursuit. Additionally, we hypothesised that boys were more concerned with social status and endorsed social demonstration goals more than girls. Indeed, boys, on average, did report higher levels of social demonstration goals $(d=.57)$. We also expected that boys reported more self-handicapping behaviours. In line with the 
prediction, boys scored higher on the Academic Self-Handicapping Scale than girls, regardless of the school subjects ( $d=.33$ for English, $d=30$ for maths).

Overall, we found consistent differences between boys and girls in their academic goals, social goals, and self-handicapping. The size of these differences did not vary systematically across different domains ${ }^{1}$.

\subsection{Relationships between gender, academic and social goals, and self- handicapping}

We proposed that boys' stronger demonstration goals and performance-avoidance goals would jointly explain their greater tendency to self-handicap. Prior to testing this new proposal, however, it is necessary to confirm the relative importance of performanceavoidance goals (vs. performance-approach goals) in predicting self-handicapping. Table 6 presents the results of commonality analysis in support of this prediction. Altogether, performance-approach and -avoidance goals accounted for $11.1 \%$ of the variance in maths self-handicapping. A substantial proportion of this variance $(61.3 \%)$ was explained by what both forms of performance goals had in common. However, performance-avoidance goals uniquely accounted for another $38.6 \%$ of the explained variance in maths self-handicapping, whereas performance-approach goals contributed only $0.1 \%$. Similarly, the analysis predicting self-handicapping in English showed a sizeable unique contribution of performance-avoidance goals relative to performanceapproach goals. Therefore, the results showed that self-handicapping was indeed primarily guided by avoidance rather than approach motives.

\footnotetext{
${ }^{1}$ Auxiliary analyses were also performed to examine whether school type moderated any of the gender differences. ANOVAs revealed significant gender $\times$ school type interaction effects on mastery goals only, such that boys attending the single-sex school were less mastery-oriented in maths and English.
} 


\begin{tabular}{lcccc}
\hline \multirow{2}{*}{ Variable } & \multicolumn{2}{c}{ Maths self-handicapping } & \multicolumn{2}{c}{ English self-handicapping } \\
\cline { 2 - 5 } & $\begin{array}{c}\text { Explained } \\
\text { variance }\end{array}$ & $\%$ of $R^{2}$ & $\begin{array}{c}\text { Explained } \\
\text { variance }\end{array}$ & $\%$ of $R^{2}$ \\
\hline Unique to PAp & $<.001$ & 0.1 & .001 & 1.5 \\
Unique to PAv & .043 & 38.6 & .030 & 37.3 \\
Common to PAp and PAv & .068 & 61.3 & .049 & 61.2 \\
Total & .111 & 100.0 & .081 & 100.0 \\
\hline
\end{tabular}

Note. PAp $=$ performance-approach goal, $\mathrm{PAv}=$ performance-avoidance goal.

Table 6. Commonality analyses with performance-approach and -avoidance goals predicting self-handicapping in maths and English

Furthermore, it was predicted that social demonstration goals would mediate gender differences in self-handicapping beyond the effects of performance-avoidance goals. To disentangle the unique contribution of each mechanism, we tested a parallel mediator model including both performance-avoidance goals and social demonstration goals as potential mediators, while controlling for the correlation between them as well as the effects of covariates (i.e., ethnicity and school type). Furthermore, to compare the relative magnitude of each mechanism, we reported effect sizes for specific indirect pathways using the proportion of the mediated effect relative to the total effect (Wen \& Fan, 2015).

The first model assessed whether gender differences in maths self-handicapping were mediated by students' general social goals and their maths-specific academic goals (see Figure 2A). The model fitted the data well, CFI $=.934$, RMSEA $=.047$, SRMR $=$ .038. Results showed that boys endorsed more social demonstration goals $(\beta=.232, p<$ $.001)$ and performance-avoidance goals in maths $(\beta=.164, p=.001)$. In turn, higher social demonstration goals $(\beta=.230, p=.001)$ and performance-avoidance goals $(\beta=$ $.205, p=.006)$ were related to increased self-handicapping behaviours in maths. Table 7 presents all other coefficients for covariates. 
[Insert Figure 2 here]

Once social and academic achievement goals were included in the model, the link between gender and maths self-handicapping $(\beta=.146, p=.002)$ was reduced to nonsignificance $(\beta=.059, p=.215)$. Bootstrap tests of indirect effects supported both proposed mediational pathways. Social demonstration goals significantly mediated the relationship between gender and maths self-handicapping ( $\beta=.053,95 \%$ CI [.023, $.099], p=.005)$. This indirect path accounted for $36.3 \%$ of the total effect of gender on self-handicapping. Independent of this mechanism, students' maths performanceavoidance goals also mediated the relationship between gender and self-handicapping ( $\beta=.034,95 \%$ CI $[.009, .076], p=.041)$, accounting for an additional $23.3 \%$ of the total effect.

\begin{tabular}{|c|c|c|c|c|c|}
\hline \multirow[b]{2}{*}{ Variable } & \multirow[b]{2}{*}{ SD goal } & \multicolumn{2}{|c|}{ Maths } & \multicolumn{2}{|c|}{ English } \\
\hline & & PAv goal & $\begin{array}{c}\text { Self- } \\
\text { handicapping }\end{array}$ & PAv goal & $\begin{array}{c}\text { Self- } \\
\text { handicapping }\end{array}$ \\
\hline Gender & $.232 * * *$ & $.164 * *$ & .059 & $.128 *$ & .075 \\
\hline School type & & & & & \\
\hline Single-sex & .027 & $-.102^{\dagger}$ & $-.102 *$ & -.037 & $-.097 *$ \\
\hline Ethnicity & & & & & \\
\hline Asian & -.076 & .001 & .066 & -.022 & $.115 * *$ \\
\hline Black & $-.058 *$ & $-.085^{*}$ & .010 & -.071 & .036 \\
\hline Mixed & .018 & .039 & -.032 & .032 & -.002 \\
\hline Goals & & & & & \\
\hline SD goal & & & $.230 * *$ & & $.287 * * *$ \\
\hline PAv goal & & & $.205 * *$ & & $.131^{\dagger}$ \\
\hline
\end{tabular}

Table 7. Standardised beta coefficients for mediation models predicting maths and English self-handicapping 
Next, we assessed whether students' general social goals and English-specific academic goals would jointly mediate the link between gender and English selfhandicapping (see Figure 2B). The model had a good fit to the data, CFI $=.936$, RMSEA $=.050$, SRMR $=.039$. Results showed that in addition to higher social demonstration goals $(\beta=.232, p<.001)$, boys adopted more performance-avoidance goals in English $(\beta=.128, p=.013)$. These social and academic goals were, in turn, associated with higher levels of self-handicapping in English $(\beta=.287, p<.001$ for social demonstration goals; $\beta=.131, p=.057$ for English performance-avoidance goals). Table 7 presents all other coefficients for covariates.

Once social goals and English-specific academic goals were taken into account, the link between gender and English self-handicapping $(\beta=.158, p=.001)$ was no longer significant $(\beta=.075, p=.106)$. Social demonstration goals again significantly mediated the relationship between gender and self-handicapping $(\beta=.066,95 \% \mathrm{CI}$ $[.034, .112], p=.001)$. This indirect path accounted for $41.8 \%$ of the total effect of gender on self-handicapping in English. Independent of this mechanism, performanceavoidance goals in English also mediated gender differences in self-handicapping $(\beta=$ $.017,95 \%$ CI $[.002, .049], p=.125)$, indicated by a bootstrapped CI that was entirely above zero. However, the strength of this indirect path was much smaller, accounting for only $10.8 \%$ of the total effect.

In summary, we found evidence that demonstration and performance-avoidance goals collectively mediated the effect of gender on self-handicapping ${ }^{2}$. Notably, the size of the indirect effects through social demonstration goals was consistently stronger.

\footnotetext{
${ }^{2}$ Following a reviewer's suggestion, we tested alternative mediation models where the performance-avoidance goal was replaced by either a composite performance goal or a performance-approach goal. In these alternative models, the indirect effects via academic goals were either smaller or non-significant.
} 


\section{Discussion}

A large body of research has examined if gender differences in school engagement can be explained by gender differences in academic motivation. Yet, students engage in schools both academically and socially, and they pursue a range of social goals that may subsequently influence their academic motivation and learning. As a result, a nearexclusive focus on academic motivation risks overlooking important gender differences in social motivation, which may further contribute to the gender gaps in school engagement and achievement. The current study addressed this issue by investigating how social goals worked alongside academic goals to explain boys' and girls' differential tendencies to self-handicap. As will be discussed, we identified gender differences in adolescents' social goals, academic goals, and self-handicapping behaviours, as well as showed the importance of social goals in accounting for gender differences in self-handicapping.

\subsection{Gender differences in adolescents' social goals, academic goals, and self- handicapping}

In line with our prediction, we found a sizeable gender difference in students' social achievement goals. Specifically, boys focused more on attaining popularity or avoiding being seen as socially undesirable. This finding adds to growing evidence that peer group status is of high priority to boys in adolescence (Ben-Eliyahu et al., 2017; LaFontana \& Cillessen, 2010; Rose \& Rudolph, 2006). This heightened need to gain peer approval may reflect that boys who deviate from group norms and values are more likely than girls to be excluded or rejected (Killen, Crystal, \& Watanabe, 2002). Dittrick and colleagues (2011) found that boys were more often harassed or bullied due to their level of popularity or lack of characteristics valued by peers. In contrast, prioritising popularity over other social goals has been shown to reduce the risk of peer rejection 
and victimization among unpopular boys but not girls (Breslend, Shoulberg, McQuade, \& Murray-Close, 2018). Collectively, these studies indicate that social demonstration goals may be more normative for boys and that seeking positive or minimizing negative evaluations from peers can have protective effects for boys, especially against social exclusion in adolescence. Nevertheless, demonstration-oriented social goals are often linked to maladaptive social adjustment, and can exert cross-domain influences and hinder students' academic adjustment (Shim et al., 2013). As a result, boys' heightened concerns about popularity and social status may also leave them more vulnerable to the maladaptive consequences of social demonstration goals.

We also replicated previous studies showing that boys are more performanceoriented than girls (Butler, 2014). In the present study, boys sought to demonstrate their ability or avoid showing a lack of ability, and these ability-validation goals have been shown to predict rather maladaptive learning behaviours (Grant \& Dweck, 2003). Given that performance-avoidance goals and social demonstration goals relate consistently to less adaptive academic outcomes, boys' joint pursuit of these goals may present a 'double jeopardy' that undermines their school engagement and achievement. Furthermore, consistent with past findings, the results replicated gender differences in self-handicapping and found that boys felt a greater need to protect their academic selfworth (Jackson, 2002). Notably, gender differences in performance goals and selfhandicapping emerged consistently in maths and English — two domains with different gender stereotypes. This robust finding supports and extends Butler's (2014) proposal that boys tend to be more oriented than girls towards proving and protecting their abilities in general, and not just in stereotypically masculine domains. Although most studies measure motivation either generally or domain specifically in one particular 
subject, simultaneously considering motivational constructs across different domains extends our understanding of the generality or specificity of motivational processes.

Inconsistent with our prediction, however, there were no significant gender differences in the endorsement of mastery goals, despite a trend for girls to be more mastery-oriented in English but not in maths. These results do not entirely contradict past research since gender differences in mastery goals did not consistently emerge, and when they did, girls were more likely than boys to hold mastery goals. Furthermore, contextual influences (e.g., stereotypes of the task domain) may interact with individual dispositions to shape one's goal orientations. In their review on gender and motivation, Hyde and Durik (2005) found that gender differences in mastery goals emerged more consistently in studies of language arts. In contrast, most studies that reported no gender differences in mastery goals focused on maths or athletics, where girls' ability is negatively stereotyped. The present results fit this pattern and suggest that there is much to be gained by investigating the extent to which patterns of gender differences are robust or limited to a specific task domain.

Given the consistent gender differences observed in this study, it is important to consider factors contributing to gender differences in adolescents' academic and social goals. Differences between boys and girls in goal orientations may be shaped by beliefs and behaviours of important socializers including parents and teachers. For example, in a study of early adolescents in the US, not only did boys espouse more personal performance goals, they also perceived a greater emphasis on performance goals from their parents (Friedel et al., 2007). Similarly, Butler (2012, Study 2) found that in addition to adopting personal performance goals, boys perceived a greater use of performance-oriented instructional practices by their teachers. In the social domain, Kiefer et al. (2013) showed that among sixth grade students, boys tended to perceive 
their teachers' instructional approach to be more performance-oriented, and they were more likely than girls to endorse social goals focusing on peer status and popularity. Nevertheless, these studies relied on self-reports from a common source. As a result, it is unclear whether the gender differences in perceptions were due to genuine differences in how adults interacted with boys and girls, or were simply a reflection of boys' and girls' own goal orientations. Future studies should utilise more appropriate design and methods to unpack how contextual influences may contribute to gender differences in adolescents' academic and social goals.

\subsection{The importance of social goals in explaining gender differences in self- handicapping}

Most importantly, we found that performance-avoidance and social demonstration goals collectively mediated the link between gender and self-handicapping. In other words, boys self-handicapped more than girls because of their stronger desire to preserve their image in both academic and social domains. By utilising commonality analysis and parallel mediator models, the present study pitted theoretically plausible mechanisms against each other (i.e., performance-approach vs. -avoidance goals; performanceavoidance vs. social demonstration goals). This approach is effective for building theories to explain motivational phenomena when multiple processes are at work, and provides strong support for the importance of social demonstration goals in mediating gender differences in self-handicapping.

The findings indicate that boys self-handicapped more than girls, in part, to avoid the appearance of incompetence in an academic domain. Although previous research has revealed positive associations between performance-avoidance goals and self-handicapping (e.g., Midgley \& Urdan, 2001), the current study provides direct evidence that it was performance-avoidance, not performance-approach, goals that 
explained gender differences in the use of self-handicapping strategies to externalise failure. As discussed in Section 4.1, boys were more oriented towards proving and protecting their ability. This hyper concern with affirming academic competence might lead them to view potential failures as more indicative of their ability (or lack thereof) and thus more threatening. As a result, boys were more motivated to engage in selfhandicapping behaviours to shift attributions for poor performance from low ability to external factors (e.g., 'I failed the exam because I didn't revise'). Additionally, situations where a student self-handicaps but still performs well provide strong evidence of one's superior ability. Thus, self-handicapping represents a win-win situation for boys who are motivated to validate their ability (see Jackson, 2002).

In addition to ability-related concerns, boys made more frequent use of selfhandicapping strategies as a result of their greater social status concerns. In the present study, social goals were examined with respect to school in general whereas academic goals and self-handicapping were assessed domain specifically. The close correspondence between measures of performance-avoidance goals and selfhandicapping would suggest greater shared variance between the two constructs. However, the fact that social demonstration goals consistently accounted for more of the effect of gender on self-handicapping provided strong support for our hypothesis. The findings suggest that the primary motivation underlying academic self-handicapping may be to preserve one's social image, with the benefit of protecting one's intellectual ability as an additional but secondary motivation. Given that boys were more preoccupied with gaining and protecting peer group status, they might be particularly motivated to self-handicap or purposely withdraw effort because academic effort is inversely related to social status during adolescence. Juvonen and Murdock (1995) found that high-ability, low-effort students were considered among the most popular 
students in secondary school. Interestingly, low-ability, low-effort students were perceived as popular as those with high ability and low effort, and more popular than their high effort peers. Similarly, Heyder and Kessels (2017) found that low-effort boys, whether high or low achievers, were rated as more popular and masculine than those displaying high effort. Once again, boys are strongly incentivised to self-handicap by withdrawing effort: it increases their popularity and perceptions of their masculinity, regardless of academic performance (see Jackson, 2003).

Although not central to this study, interesting associations were also observed between covariates and key variables in the model. For example, students attending single-sex schools were less likely to self-handicap. This effect might be driven by the higher average achievement of students attending single-sex schools, as the relationship between self-handicapping and achievement may be reciprocal (Martin, Marsh, \& Debus, 2001). Additionally, there was no correlation between students' social demonstration goals and the type of school they attended. The fact that demonstration goals did not vary with the gender composition of peers or average levels of SES and achievement points to the ubiquity of peer status concerns during adolescence.

Results further inform the debate over the empirical distinctiveness of performance-approach and -avoidance goals (Linnenbrink-Garcia et al., 2012). A strong correlation was found between the two performance goals ( $\phi s=.80$ and .86$)$, which was comparable to those reported in recent studies (e.g., $\phi=.88$ in Bong et al., 2013). Nevertheless, distinguishing between performance-approach and -avoidance goals improved the model fit of CFAs in the current study. Additionally, performanceapproach and -avoidance goals differentially predicted self-handicapping as well as differentially mediated the relationship between gender and self-handicapping. These results provide clear support for the distinction between the two performance goals, and 
the overlap between them may be explained by a shared normative evaluation focus (Janke et al., 2016) and their joint activation in achievement settings (see Law, Elliot, \& Murayama, 2012).

Together, these findings advance our understanding of both self-handicapping and gender-related influences on motivational variables and processes. Past studies have shown that gender differences in self-handicapping can be partially explained by the different value males and females ascribe to effort (McCrea, Hirt, \& Milner, 2008). Drawing on a social cognitive approach to motivation, the current study identified additional factors that predispose boys to self-handicap more than girls, that is, gender differences in performance-avoidance and social demonstration goals. This suggests that the gendered tendencies to self-handicap are potentially changeable and amenable to interventions that target students' academic and social achievement goals.

\subsection{Educational implications}

The present study has implications for teachers and their classroom practices. Although primary school teachers tend to view themselves as facilitators of both knowledge and social development, secondary school teachers focus much more on content instruction (Roeser, Marachi, \& Gehlbach, 2002). This study highlights the importance of attending to students' social goals even in secondary school settings. In addition, research on classroom goal structures has shown that students construct their academic and social goals within the broader classroom environment. In contexts where teachers make greater use of performance-oriented instructional practices (e.g., emphasis on grades, ability, and social comparison), students are more likely to adopt performance goals (Meece, Anderman, \& Anderman, 2006). Similarly, Shim and colleagues (2013) found that students were also more oriented towards social demonstration goals when they perceived high levels of competition and social comparison of performance in their 
classroom. These findings suggest that teachers can simultaneously promote adaptive academic and social goal pursuits among all students (not just boys) by creating a more mastery-oriented learning environment (e.g., emphasis on effort, cooperation, improvement and the value of mistakes).

\subsection{Strengths, limitations, and future directions}

The present study tested hypotheses using a diverse, well-powered sample. In addition, we used domain-specific measures of academic goals and self-handicapping to assess the generality of our results in two gender-typed subjects. This enhances the validity and generalizability of the study, and suggests that our findings are not limited to a specific subject area or a particular sample from one school.

However, the study is not without its limitations. First, although the effect of ethnicity was statistically controlled for in our analyses, it is important that future research verify the current results in other cultural contexts, given that adopting performance-avoidance and demonstration-avoidance goals seems to be less maladaptive in Asian contexts (King, 2016b; Liem, 2016). Second, this study is crosssectional in nature and thus can only provide evidence for associations rather than causation. Future research should measure mediators and outcomes at different time points to strengthen the causal inference. Additionally, only measures of social demonstration goals were included, and they did not adequately distinguish between demonstration-approach and -avoidance goals. Future studies should incorporate social development goals as well as more sensitive measures of social demonstration goals to clarify which form of the demonstration goals mediates the relationship between gender and self-handicapping. Although no gender differences in mastery goals were found in the current study, future studies should continue to probe whether gender differences in mastery goals could further explain why girls tend to refrain from self-handicapping 
(Schwinger \& Stiensmeier-Pelster, 2011). Finally, the present study focused squarely on the relationship between gender, academic and social goals, and self-handicapping. Future studies can include and control for other important predictors of selfhandicapping, such as self-esteem, to strengthen the conclusion of this study. In addition, a broader range of self-reported or objectively measured academic outcomes can be used to examine the cross-domain influences of social achievement goals.

Moreover, it may be fruitful for researchers to continue reaching across the boundaries between academic and social motivation to understand gender gaps in performance and participation. For example, boys are less likely than girls to seek help with their academic work when needed, even though help-seeking behaviour is positively associated with academic achievement. Previous research has shown that performance goals and social demonstration goals are linked to perceived threats and avoidance of help-seeking (Ryan, Hicks, \& Midgley, 1997). Thus, gender differences in social and academic goals may also account for the gender differences in help-seeking behaviour. Additionally, research drawing on expectancy-value theory has investigated gender differences in competence and value beliefs to understand gendered subject choices (e.g., Watt et al., 2012). It is possible that students' social achievement goals may further contribute to gender differences in the selection of different subjects. To the extent that boys and young men are oriented towards gaining social status and recognition in their social groups (i.e., demonstration-approach goals), they may be more motivated to engage in maths-related subjects, which often lead to well-paid, high-status future careers. To the extent that boys and young men are sensitive to or concerned about signs of disapproval from peers (i.e., demonstration-avoidance goals), they may be less likely to study education or nursing, which are associated with lowerstatus, stereotypically female professions. Future work can include measures of social 
achievement goals to test these claims. Overall, simultaneously considering the influence of social and academic motivation may extend our understanding of the gender gaps in education. 


\section{References}

Anderman, L. H., \& Anderman, E. M. (1999). Social predictors of changes in students' achievement goal orientations. Contemporary Educational Psychology, 24, 2137. https://doi.org/10.1006/ceps.1998.0978

Baumeister, R. F., \& Leary, M. R. (1995). The need to belong: Desire for interpersonal attachments as a fundamental human motivation. Psychological Bulletin, 117, 497-529. https://doi.org/10.1037/0033-2909.117.3.497

Ben-Eliyahu, A., Linnenbrink-Garcia, L., \& Putallaz, M. (2017). The intertwined nature of adolescents' social and academic lives: Social and academic goal orientations. Journal of Advanced Academics, 28, 66-93. https://doi.org/10.1177/1932202X16685307

Bong, M., Woo, Y., \& Shin, J. (2013). Do students distinguish between different types of performance goals? The Journal of Experimental Education, 81, 464-489. https://doi.org/10.1080/00220973.2012.745464

Breslend, N. L., Shoulberg, E. K., McQuade, J. D., \& Murray-Close, D. (2018). Social costs for wannabes: Moderating effects of popularity and gender on the links between popularity goals and negative peer experiences. Journal of Youth and Adolescence, 47, 1894-1906. https://doi.org/10.1007/s10964-018-0810-0

Bugler, M., McGeown, S. P., \& St Clair-Thompson, H. (2015). Gender differences in adolescents' academic motivation and classroom behaviour. Educational Psychology, 35, 541-556. https://doi.org/10.1080/01443410.2013.849325

Butler, R. (2006). Are mastery and ability goals both adaptive? Evaluation, initial goal construction and the quality of task engagement. British Journal of Educational Psychology, 76, 595-611. https://doi.org/10.1348/000709905X52319 
Butler, R. (2012). Striving to connect: Extending an achievement goal approach to teacher motivation to include relational goals for teaching. Journal of Educational Psychology, 104, 726-742. https://doi.org/10.1037/a0028613

Butler, R. (2014). Motivation in educational contexts: Does gender matter? In L. S. Liben \& R. S. Bigler (Eds.), Advances in child development and behavior (Vol. 47, pp. 1-41). San Diego, CA: Academic Press.

Butler, R., \& Hasenfratz, L. (2017). Gender and competence motivation. In A. J. Elliot, C. S. Dweck, \& D. S. Yeager (Eds.), Handbook of competence and motivtion (2nd ed., pp. 489-511). New York, NY: Guilford Press.

Chen, F. F. (2007). Sensitivity of goodness of fit indexes to lack of measurement invariance. Structural Equation Modeling, 14, 464-504. https://doi.org/10.1080/10705510701301834

Cohen, J. (1992). A power primer. Psychological Bulletin, 112, 155-159. https://doi.org/10.1037/0033-2909.112.1.155

Covington, M. V., \& Omelich, C. L. (1979). Effort: The double-edged sword in school achievement. Journal of Educational Psychology, 71, 169-182. https://doi.org/10.1037/0022-0663.71.2.169

Deci, E. L., \& Ryan, R. M. (2000). The 'what' and 'why' of goal pursuits: Human needs and the self-determination of behavior. Psychological Inquiry, 11, 227268. https://doi.org/10.1207/S15327965PLI1104_01

Dietrich, D. (1995). Gender differences in self-handicapping: Regardless of academic or social competence implications. Social Behavior and Personality, 23, 403-410. https://doi.org/10.2224/sbp.1995.23.4.403

Dittrick, C., Closson, L. M., Shumka, E., \& Hymel, S. C. (2011, June). Middle school students ' perceptions of their victimization experiences. Poster session presented 
at the Annual Convention of the Canadian Psychological Association, Toronto, ON.

Dweck, C. S. (1986). Motivational processes affecting learning. American Psychologist, 41, 1040-1048. https://doi.org/10.1037/0003-066X.41.10.1040

Elliot, A. J. (2005). A conceptual history of the achievement goal construct. In A. J. Elliot \& C. S. Dweck (Eds.), Handbook of competence and motivation (pp. 5272). New York, NY: Guilford Press.

Elliot, A. J., \& Harackiewicz, J. M. (1996). Approach and avoidance achievement goals and intrinsic motivation: A mediational analysis. Journal of Personality and Social Psychology, 70, 461-475. https://doi.org/10.1037/0022-3514.70.3.461

Friedel, J. M., Cortina, K. S., Turner, J. C., \& Midgley, C. (2007). Achievement goals, efficacy beliefs and coping strategies in mathematics: The roles of perceived parent and teacher goal emphases. Contemporary Educational Psychology, 32, 434-458. https://doi.org/10.1016/j.cedpsych.2006.10.009

Fritz, M. S., \& MacKinnon, D. P. (2007). Required sample size to detect the mediated effect. Psychological Science, 18, 233-239. https://doi.org/10.1111/j.14679280.2007.01882.x

Grant, H., \& Dweck, C. S. (2003). Clarifying achievement goals and their impact. Journal of Personality and Social Psychology, 85, 541-553. https://doi.org/10.1037/0022-3514.85.3.541

Gregorich, S. E. (2006). Do self-report instruments allow meaningful comparisons across diverse population groups? Testing measurement invariance using the confirmatory factor analysis framework. Medical Care, 44, S78-S94. https://doi.org/10.1097/01.mlr.0000245454.12228.8f 
Heyder, A., \& Kessels, U. (2017). Boys don't work? On the psychological benefits of showing low effort in high school. Sex Roles, 77, 72-85. https://doi.org/10.1007/s11199-016-0683-1

Hirt, E. R., McCrea, S. M., \& Boris, H. I. (2003). 'I know you self-handicapped last exam': Gender differences in reactions to self-handicapping. Journal of Personality and Social Psychology, 84, 177-193. https://doi.org/10.1037/00223514.84.1.177

Hu, L., \& Bentler, P. M. (1999). Cutoff criteria for fit indexes in covariance structure analysis: Conventional criteria versus new alternatives. Structural Equation Modeling, 6, 1-55. https://doi.org/10.1080/10705519909540118

Huang, C. (2011). Achievement goals and achievement emotions: A meta-analysis. Educational Psychology Review, 23, 359-388. https://doi.org/10.1007/s10648$011-9155-\mathrm{x}$

Hulleman, C. S., Schrager, S. M., Bodmann, S. M., \& Harackiewicz, J. M. (2010). A meta-analytic review of achievement goal measures: Different labels for the same constructs or different constructs with similar labels? Psychological Bulletin, 136, 422-449. https://doi.org/10.1037/a0018947

Hyde, J. S., \& Durik, A. M. (2005). Gender, competence, and motivation. In A. J. Elliot \& C. S. Dweck (Eds.), Handbook of competence and motivation (pp. 375-391). New York, NY: Guilford Press.

Jackson, C. (2002). 'Laddishness' as a self-worth protection strategy. Gender and Education, 14, 37-50. https://doi.org/10.1080/09540250120098870 Jackson, C. (2003). Motives for 'laddishness' at school: Fear of failure and fear of the 'feminine'. British Educational Research Journal, 29, 583-598. https://doi.org/10.1080/01411920301847 
Jackson, C. (2006). Lads and ladettes in school: Gender and a fear of failure.

Maidenhead: Open University Press.

[dataset] Jackson, C. (2008). Laddishness and Self-Worth Protection, 2004. [data collection]. UK Data Service. SN: 5848, https://doi.org/10.5255/UKDA-SN$5848-1$

Janke, S., Nitsche, S., Praetorius, A.-K., Benning, K., Fasching, M., Dresel, M., \& Dickhäuser, O. (2016). Deconstructing performance goal orientations: The merit of a dimensional approach. Learning and Individual Differences, 50, 133-146. https://doi.org/10.1016/j.lindif.2016.08.013

Juvonen, J., \& Murdock, T. B. (1995). Grade-level differences in the social value of effort: Implications for self-presentation tactics of early adolescents. Child Development, 66, 1694-1705. https://doi.org/10.1111/j.14678624.1995.tb00959.x

Kenney-Benson, G. A., Pomerantz, E. M., Ryan, A. M., \& Patrick, H. (2006). Sex differences in math performance: The role of children's approach to schoolwork. Developmental Psychology, 42, 11-26. https://doi.org/10.1037/00121649.42 .1 .11

Kiefer, S. M., Matthews, Y. T., Montesino, M., Arango, L., \& Preece, K. K. (2013). The effects of contextual and personal factors on young adolescents' social goals. The Journal of Experimental Education, 81, 44-67. https://doi.org/10.1080/00220973.2011.630046

Kiefer, S. M., \& Ryan, A. M. (2008). Striving for social dominance over peers: The implications for academic adjustment during early adolescence. Journal of Educational Psychology, 100, 417-428. https://doi.org/10.1037/00220663.100 .2 .417 
Killen, M., Crystal, D. S., \& Watanabe, H. (2002). Japanese and American children's evaluations of peer exclusion, tolerance of differences, and prescriptions for conformity. Child Development, 73, 1788-1802. https://doi.org/10.1111/14678624.t01-1-00506

King, R. B. (2016a). Gender differences in motivation, engagement and achievement are related to students' perceptions of peer-but not of parent or teacherattitudes towards school. Learning and Individual Differences, 52, 60-71. https://doi.org/10.1016/j.lindif.2016.10.006

King, R. B. (2016b). Is a performance-avoidance achievement goal always maladaptive? Not necessarily for collectivists. Personality and Individual Differences, 99, 190-195. https://doi.org/10.1016/j.paid.2016.04.093

LaFontana, K. M., \& Cillessen, A. H. N. (2010). Developmental changes in the priority of perceived status in childhood and adolescence. Social Development, 19, 130147. https://doi.org/10.1111/j.1467-9507.2008.00522.x

Lam, S., Jimerson, S., Kikas, E., Cefai, C., Veiga, F. H., Nelson, B., ... Zollneritsch, J. (2012). Do girls and boys perceive themselves as equally engaged in school? The results of an international study from 12 countries. Journal of School Psychology, 50, 77-94. https://doi.org/10.1016/j.jsp.2011.07.004

Law, W., Elliot, A. J., \& Murayama, K. (2012). Perceived competence moderates the relation between performance-approach and performance-avoidance goals. Journal of Educational Psychology, 104, 806-819. https://doi.org/10.1037/a0027179

Leondari, A., \& Gonida, E. (2007). Predicting academic self-handicapping in different age groups: The role of personal achievement goals and social goals. British 
Journal of Educational Psychology, 77, 595-611.

https://doi.org/10.1348/000709906X128396

Liem, G. A. D. (2016). Academic and social achievement goals: Their additive, interactive, and specialized effects on school functioning. British Journal of Educational Psychology, 86, 37-56. https://doi.org/10.1111/bjep.12085

Linnenbrink-Garcia, L., Middleton, M. J., Ciani, K. D., Easter, M. A., O’Keefe, P. A., \& Zusho, A. (2012). The strength of the relation between performance-approach and performance-avoidance goal orientations: Theoretical, methodological, and instructional implications. Educational Psychologist, 47, 281-301. https://doi.org/10.1080/00461520.2012.722515

Martin, A. J., Marsh, H. W., \& Debus, R. L. (2001). Self-handicapping and defensive pessimism: Exploring a model of predictors and outcomes from a self-protection perspective. Journal of Educational Psychology, 93, 87-102. https://doi.org/10.1037/0022-0663.93.1.87

McCrea, S. M., Hirt, E. R., Hendrix, K. L., Milner, B. J., \& Steele, N. L. (2008). The worker scale: Developing a measure to explain gender differences in behavioral self-handicapping. Journal of Research in Personality, 42, 949-970. https://doi.org/10.1016/j.jrp.2007.12.005

McCrea, S. M., Hirt, E. R., \& Milner, B. J. (2008). She works hard for the money: Valuing effort underlies gender differences in behavioral self-handicapping. Journal of Experimental Social Psychology, 44, 292-311. https://doi.org/10.1016/j.jesp.2007.05.006

McNeish, D. (2018). Thanks coefficient alpha, we'll take it from here. Psychological Methods, 23, 412-433. https://doi.org/10.1037/met0000144 
Meece, J. L., Anderman, E. M., \& Anderman, L. H. (2006). Classroom goal structure, student motivation, and academic achievement. Annual Review of Psychology, 57, 487-503. https://doi.org/10.1146/annurev.psych.56.091103.070258

Midgley, C., Maehr, M. L., Hruda, L. Z., Anderman, E., Anderman, L., Freeman, K. E., ... Urdan, T. (2000). Manual for the Patterns of Adaptive Learning Scales. Ann Arbor, MI: University of Michigan. Retrieved from http://www.umich.edu/ pals/PALS\%202000_V12Word97.pdf

Midgley, C., \& Urdan, T. (2001). Academic self-handicapping and achievement goals: A further examination. Contemporary Educational Psychology, 26, 61-75. https://doi.org/10.1006/ceps.2000.1041

Mouratidis, A. A., \& Sideridis, G. D. (2009). On social achievement goals: Their relations with peer acceptance, classroom belongingness, and perceptions of loneliness. The Journal of Experimental Education, 77, 285-308. https://doi.org/10.3200/JEXE.77.3.285-308

Muthén, L. K., \& Muthén, B. O. (1998-2017). Mplus User's Guide (8th ed.). Los Angeles, CA: Muthén \& Muthén.

Nicholls, J. G. (1984). Achievement motivation: Conceptions of ability, subjective experience, task choice, and performance. Psychological Review, 91, 328-346. https://doi.org/10.1037/0033-295X.91.3.328

Nie, Y., \& Liem, G. A. D. (2013). Extending antecedents of achievement goals: The double-edged sword effect of social-oriented achievement motive and gender differences. Learning and Individual Differences, 23, 249-255. https://doi.org/10.1016/j.lindif.2012.10.006

Nimon, K., Lewis, M., Kane, R., \& Haynes, R. M. (2008). An R package to compute commonality coefficients in the multiple regression case: An introduction to the 
package and a practical example. Behavior Research Methods, 40, 457-466. https://doi.org/10.3758/BRM.40.2.457

OECD (2015). Where are the gender gaps in education and employment? In Education at a Glance: OECD Indicators (pp. 188-204). Paris: OECD Publishing. Retrieved from http://dx.doi.org/10.1787/eag-2015-16-en

Patrick, H., Anderman, L. H., \& Ryan, A. M. (2002). Social motivation and the classroom social environment. In C. Midgley (Ed.), Goals, goal structures, and patterns of adaptive learning (pp. 85-108). New York, NY: Routledge.

Patrick, H., Ryan, A. M., \& Kaplan, A. (2007). Early adolescents' perceptions of the classroom social environment, motivational beliefs, and engagement. Journal of Educational Psychology, 99, 83-98. https://doi.org/10.1037/0022-0663.99.1.83

Payne, S. C., Youngcourt, S. S., \& Beaubien, J. M. (2007). A meta-analytic examination of the goal orientation nomological net. Journal of Applied Psychology, 92, 128-150. https://doi.org/10.1037/0021-9010.92.1.128

Preacher, K. J., \& Hayes, A. F. (2008). Asymptotic and resampling strategies for assessing and comparing indirect effects in multiple mediator models. Behavior Research Methods, 40, 879-891. https://doi.org/10.3758/BRM.40.3.879

Preckel, F., Goetz, T., Pekrun, R., \& Kleine, M. (2008). Gender differences in gifted and average-ability students: Comparing girls' and boys' achievement, selfconcept, interest, and motivation in mathematics. Gifted Child Quarterly, 52, 146-159. https://doi.org/10.1177/0016986208315834

Revelle, W., \& Zinbarg, R. E. (2009). Coefficients alpha, beta, omega, and the glb: Comments on Sijtsma. Psychometrika, 74, 145-154. https://doi.org/10.1007/s11336-008-9102-z 
Rhodewalt, F. (1994). Conceptions of ability, achievement goals, and individual differences in self-handicapping behavior: On the application of implicit theories. Journal of Personality, 62, 67-85. https://doi.org/10.1111/j.14676494.1994.tb00795.x

Roeser, R., Marachi, R., \& Gehlbach, H. (2002). A goal theory perspective on teachers' professional identities and the contexts of teaching. In C. Midgley (Ed.), Goals, goal structures, and patterns of adaptive learning (pp. 205-242). New York, NY: Routledge.

Rose, A. J., \& Rudolph, K. D. (2006). A review of sex differences in peer relationship processes: Potential trade-offs for the emotional and behavioral development of girls and boys. Psychological Bulletin, 132, 98-131. https://doi.org/10.1037/0033-2909.132.1.98

Ryan, A. M., Hicks, L., \& Midgley, C. (1997). Social goals, academic goals, and avoiding seeking help in the classroom. The Journal of Early Adolescence, 17, 152-171. https://doi.org/10.1177/0272431697017002003

Ryan, A. M., \& Shim, S. S. (2006). Social achievement goals: The nature and consequences of different orientations towards social competence. Personality and Social Psychology Bulletin, 32, 1246-1263. https://doi.org/10.1177/0146167206289345

Ryan, A. M., \& Shim, S. S. (2008). An exploration of young adolescents' social achievement goals and social adjustment in middle school. Journal of Educational Psychology, 100, 672-687. https://doi.org/10.1037/00220663.100.3.672

Ryan, A. M., \& Shin, H. (2011). Help-seeking tendencies during early adolescence: An examination of motivational correlates and consequences for achievement. 
Learning and Instruction, 21, 247-256.

https://doi.org/10.1016/j.learninstruc.2010.07.003

Schwinger, M., \& Stiensmeier-Pelster, J. (2011). Prevention of self-handicapping The protective function of mastery goals. Learning and Individual Differences, 21, 699-709. https://doi.org/10.1016/j.lindif.2011.09.004

Schwinger, M., Wirthwein, L., Lemmer, G., \& Steinmayr, R. (2014). Academic selfhandicapping and achievement: A meta-analysis. Journal of Educational Psychology, 106, 744-761. https://doi.org/10.1037/a0035832

Senko, C., \& Dawson, B. (2017). Performance-approach goal effects depend on how they are defined: Meta-analytic evidence from multiple educational outcomes. Journal of Educational Psychology, 109, 574-598.

https://doi.org/10.1037/edu0000160

Shim, S. S., Cho, Y., \& Wang, C. (2013). Classroom goal structures, social achievement goals, and adjustment in middle school. Learning and Instruction, 23, 69-77. https://doi.org/10.1016/j.learninstruc.2012.05.008

Shim, S. S., \& Finch, W. H. (2014). Academic and social achievement goals and early adolescents' adjustment: A latent class approach. Learning and Individual Differences, 30, 98-105. https://doi.org/10.1016/j.lindif.2013.10.015

Stoet, G., \& Geary, D. C. (2015). Sex differences in academic achievement are not related to political, economic, or social equality. Intelligence, 48, 137-151. https://doi.org/10.1016/j.intell.2014.11.006

Strand, S. (2014). Ethnicity, gender, social class, and achievement gaps at age 16: Intersectionality and 'getting it' for the white working class. Research Papers in Education, 29, 131-171. https://doi.org/10.1080/02671522.2013.767370 
Urdan, T. (2004). Predictors of academic self-handicapping and achievement:

Examining achievement goals, classroom goal structures, and culture. Journal of Educational Psychology, 96, 251-264. https://doi.org/10.1037/00220663.96 .2 .251

Urdan, T., \& Midgley, C. (2001). Academic self-handicapping: What we know, what more there is to learn. Educational Psychology Review, 13, 115-138. https://doi.org/10.1023/A:1009061303214

Vansteenkiste, M., Lens, W., Elliot, A. J., Soenens, B., \& Mouratidis, A. (2014). Moving the achievement goal approach one step forward: Towards a systematic examination of the autonomous and controlled reasons underlying achievement goals. Educational Psychologist, 49, 153-174.

https://doi.org/10.1080/00461520.2014.928598

Voyer, D., \& Voyer, S. D. (2014). Gender differences in scholastic achievement: A meta-analysis. Psychological Bulletin, 140, 1174-1204. https://doi.org/10.1037/a0036620

Watt, H. M. G., Shapka, J. D., Morris, Z. A., Durik, A. M., Keating, D. P., \& Eccles, J. S. (2012). Gendered motivational processes affecting high school mathematics participation, educational aspirations, and career plans: A comparison of samples from Australia, Canada, and the United States. Developmental Psychology, 48, 1594-1611. https://doi.org/10.1037/a0027838

Wen, Z., \& Fan, X. (2015). Monotonicity of effect sizes: Questioning kappa-squared as mediation effect size measure. Psychological Methods, 20, 193-203. https://doi.org/10.1037/met0000029

Wentzel, K. R. (2017). Peer relationships, motivation, and academic performance at school. In A. J. Elliot, C. S. Dweck, \& D. S. Yeager (Eds.), Handbook of 
competence and motivation (2nd ed., pp. 586-603). New York, NY: Guilford Press.

Wormington, S. V., \& Linnenbrink-Garcia, L. (2017). A new look at multiple goal pursuit: The promise of a person-centered approach. Educational Psychology Review, 29, 407-445. https://doi.org/10.1007/s10648-016-9358-2

Younger, M., Warrington, M., \& McLellan, R. (2005). Raising boys' achievement in secondary schools: Issues, dilemmas and opportunities. Maidenhead: Open University Press. 


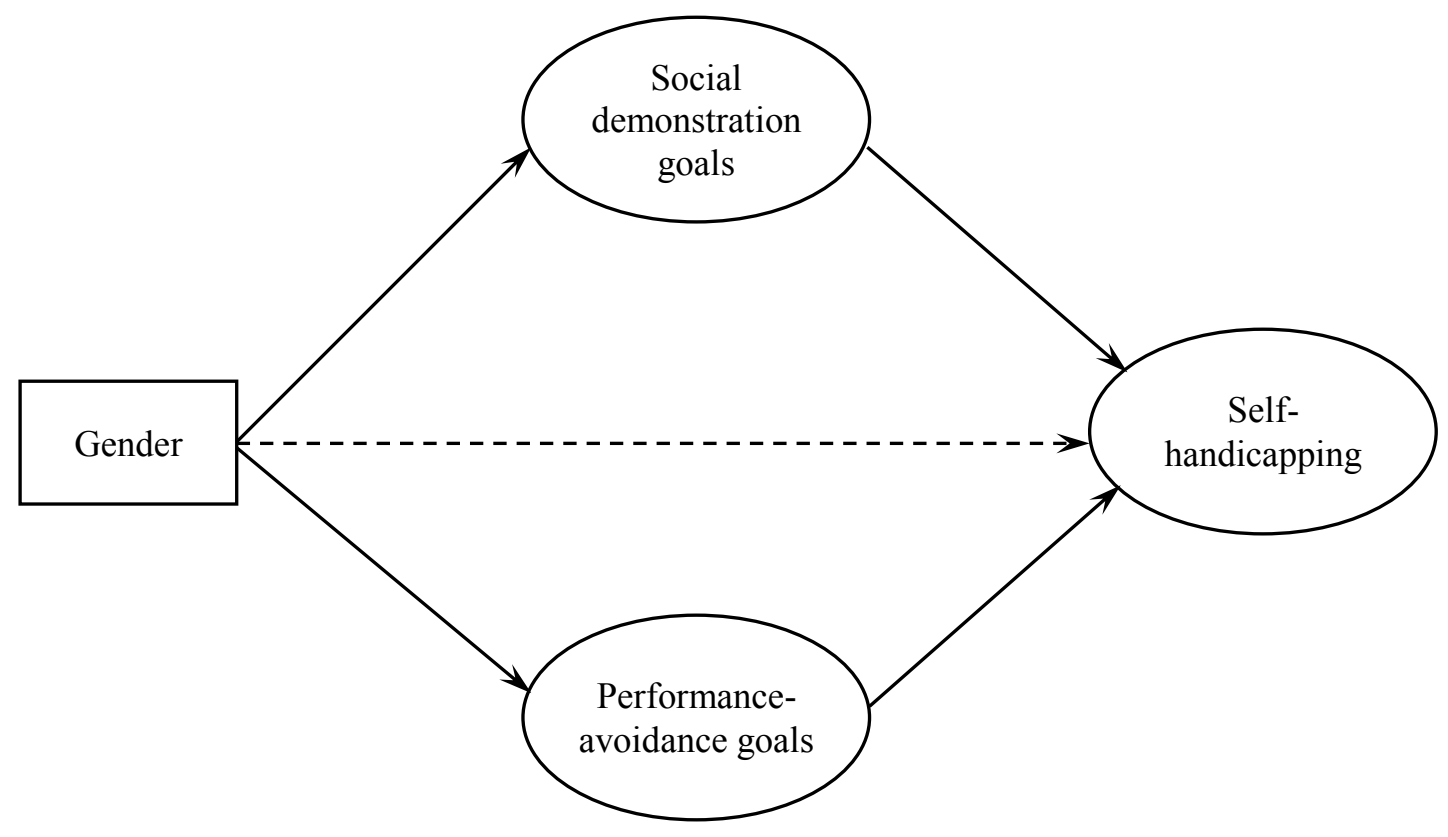

Figure 1. Conceptual model depicting the hypothesised relationships among key variables 


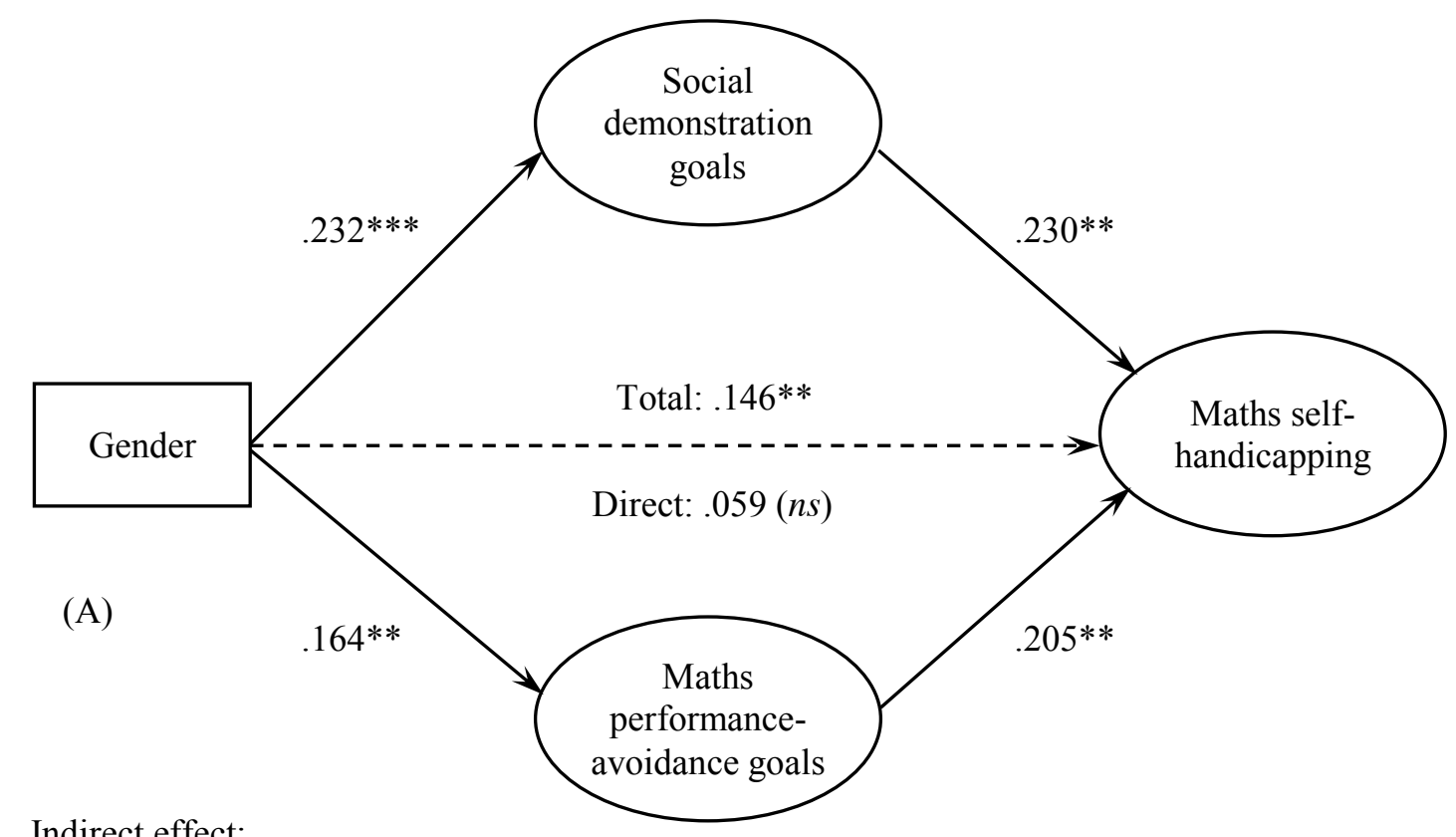

1) Specific indirect effect via social demonstration goals $(\beta=.053$, CI $[.023, .099], p=.005)$

2) Specific indirect effect via maths performance-avoidance goals ( $\beta=.034$, CI $[.009, .076], p=.041)$

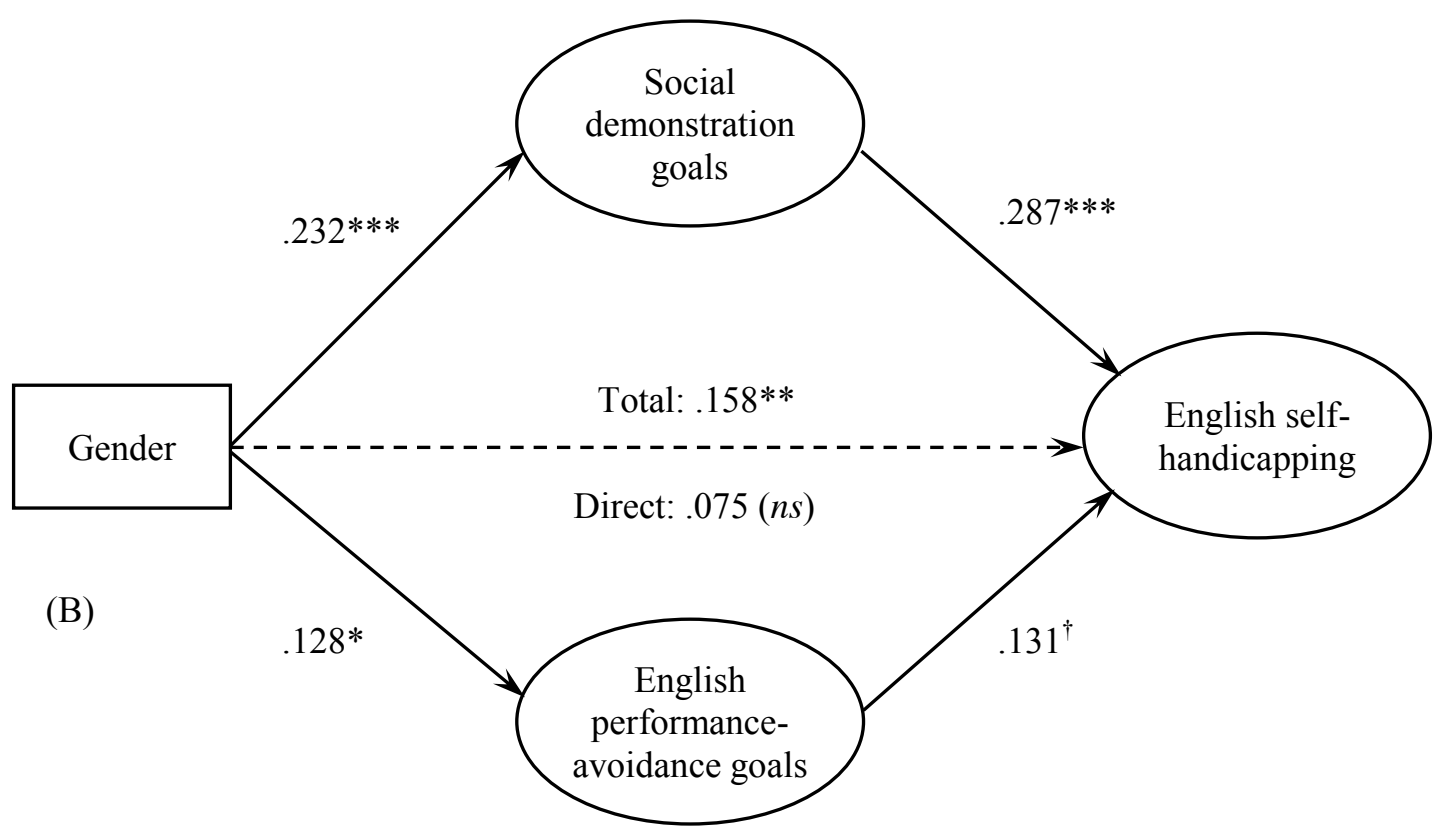

Indirect effect:

1) Specific indirect effect via social demonstration goals ( $\beta=.066$, CI $[.034, .112], p=.001)$

2) Specific indirect effect via English performance-avoidance goals $(\beta=.017$, CI [.002, .049], $p=$ $.125)$

Figure 2. Structural equation models showing the mediating role of academic and social achievement goals between gender and self-handicapping. Note. ${ }^{\dagger} p<.06,{ }^{*} p<.05, * * p<.01$, $* * * p<.001$. 
Beyond academic achievement goals: The importance of social achievement goals in explaining gender differences in self-handicapping

\section{Highlights}

Adolescent boys and girls pursued different social and academic goals at school.

Compared to girls, boys reported more social demonstration goals.

Boys adopted more performance goals in maths and English.

Boys reported greater self-handicapping tendencies in maths and English.

Social demonstration goals explained gender differences in self-handicapping. 